\title{
(- OPEN ACCESS \\ Focused assessment with sonography for trauma (FAST) identifies liver injury following cardiopulmonary resuscitation
}

\author{
Hiroshi Nashiki, ${ }^{1}$ Yoshiharu Miyate, ${ }_{1}$ Yousuke Terui, ${ }^{2}$ Masayuki Otani ${ }^{2}$
}

${ }^{1}$ Department of Critical Care Medicine, Iwate Prefectural Central Hospital, Morioka, Japan ${ }^{2}$ Department of Cardiology, Iwate Prefectural Central Hospital, Morioka, Japan

\section{Correspondence to} Dr Hiroshi Nashiki, nashikihiroshi@chuo-hp.jp

Accepted 4 July 2017
CrossMark

To cite: Nashiki H, Miyate $Y$, Terui Y, et al. BMJ Case Rep Published Online First: [please include Day Month Year]. doi:10.1136/bcr-2017 221421

\section{SUMMARY}

Liver trauma is a recognised rare complication of cardiopulmonary resuscitation (CPR) and may be difficult to detect. We report a case of intraperitoneal haemorrhage due to liver injury following CPR in a 50 -year-old man admitted to the intensive care unit. The haemorrhage was diagnosed with focused assessment with sonography for trauma (FAST). FAST can rapidly and easily diagnose liver injury. FAST is recommended for excluding haemoperitoneum in patients who are haemodynamically unstable after resuscitation.

\section{BACKGROUND}

Liver trauma is a rare complication of cardiopulmonary resuscitation (CPR) that can be difficult to detect. ${ }^{1}$ We report a case of intraperitoneal haemorrhage due to liver injury following CPR. On arrival to the intensive care unit (ICU), the patient was diagnosed with liver damage via focused assessment with sonography for trauma (FAST). The present case illustrates the utility of FAST for excluding haemoperitoneum in patients who are hemodynamically unstable after resuscitation.

\section{CASE PRESENTATION}

A 50-year-old man suffered a seizure, which was witnessed by bystanders, while walking on the street. The patient became unresponsive and the bystanders performed CPR at the scene. Emergency services arrived $10 \mathrm{~min}$ later; however, automated external defibrillator did not work. The emergency personnel commenced CPR and the patient arrived at our hospital $20 \mathrm{~min}$ following seizure onset. By the time the patient presented to the emergency department, he was unresponsive, apnoeic and areflexic with a Glasgow Coma Scale score of 3 . He had no medical history and took no medications. ECG revealed asystole. Ten minutes after presenting to the emergency room, $1 \mathrm{mg}$ epinephrine was intravenously administered and the patient experienced return of spontaneous circulation (ROSC). The patient was emergently intubated. Blood test revealed haemoglobin level of $14.6 \mathrm{~g} / \mathrm{dL}$ and haematocrit (Ht) level of $44.2 \%$ at arrival. No coagulation abnormalities were observed. ECG revealed ST reduction of the precordial leads and ST elevation in aVR inductionafter resuscitation. The patient was diagnosed with cardiac arrest due to acute coronary syndrome. FAST was not administered this time. A CT was ordered; however, the patient exhibited ventricular fibrillation and was moved to catheter room.

The patient underwent emergency catheter examination and percutaneous coronary angioplasty under percutaneous cardiopulmonary support (PCPS), which revealed 90\% obstruction of the anterior descending branches. He exhibited ROSC and was admitted to the ICU after intraaortic balloon pumping (IABP); subsequently, his blood pressure decreased. ECG revealed normal cardiac contractile forces outside the anterior descending branch areas. The patient continued to exhibit abdominal distention and decreasing Ht. This time we performed FAST, which revealed echo-free space around the liver and the spleen. Contrast CT examination revealed bloody ascites around the liver and the spleen, and we diagnosed intra-abdominal bleeding. A linear contrast effect was observed in the vicinity of the hepatic sickle ligament in the early phase of the contrast (figure 1). We diagnosed liver haemorrhage because the contrast effect was recognised as late contrast phase (figure 2). There was no apparent damage in the liver parenchyma. Conservative treatment was chosen because there is no indication of apparent liver parenchymal damage, and the patient's blood pressure increased following transfusion.

\section{OUTCOME AND FOLLOW-UP}

We withdrew PCPS on day 2 and IABP on day 3, with no decline in circulatory or respiratory conditions. The patient's state of consciousness did not improve, and he was diagnosed with irreversible anoxic brain injury via head CT. Electroencephalogram results were also consistent with anoxic brain injury. Tracheotomy was performed on day 11, and the patient was discharged from the ICU on day 13.

\section{DISCUSSION}

We report on a case of intraperitoneal bleeding due to liver injury following CPR. Although isolated cases of liver injury secondary to chest compressions appear in the literature, they are extremely rare. ${ }^{1}$ Hepatic injury is the most common CPR-related intra-abdominal complication, with an approximate incidence of $0.6 \% .^{1-7}$

In the present case, CPR was initiated by bystanders; however, it has been reported that there is no significant difference in the frequency 
A

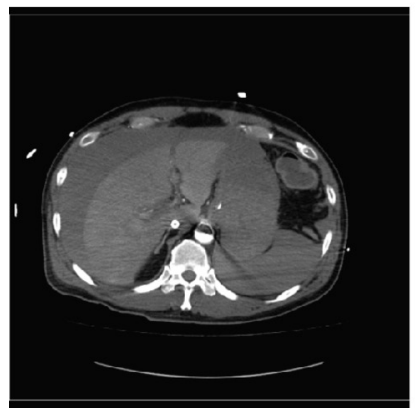

B

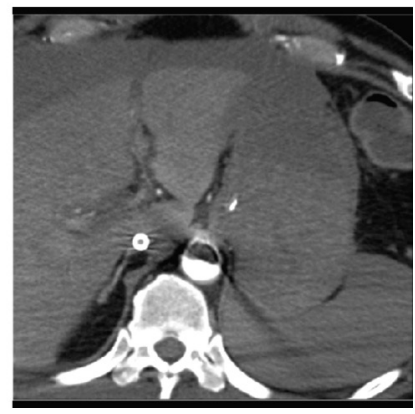

Figure $1 \quad(A, B)$ Early phase abdominal CT with contrast. A linear contrast effect is recognised near the liver sickle ligament. Abdominal fluid absorption value is approximately $50-70 \mathrm{HU}$.

of liver damage that results from CPR administered by bystander (ie, non-healthcare worker) and CPR administered by medical personnel. ${ }^{1}$ The study reported hepatic injury during CPR with decreased Ht levels noted on hospital arrival. ${ }^{1}$ However, in the present case, there was no decrease in Ht levels noted when the patient arrived at the hospital. Had our patient been considered as a CPA survivor and a trauma patient, FAST could have potentially detected liver injury earlier.

The FAST examination is easily performed in emergency and ICU settings. It is safe and able to detect peritoneal fluid in the right upper quadrant. FAST is widely considered to be the best initial imaging method, particularly for patients who are hemodynamically unstable. ${ }^{8}$

Limitations of FAST include operator-dependency and occasional failure to detect fluid volumes less than $200-500 \mathrm{~mL}{ }^{9}$ Focused attention on cardiac status following arrest may distract from consideration of the need for further workup. Therefore, there may be delays in diagnosing intra-abdominal haemorrhage and liver injury or they may be completely missed. Thus, the incidence of these conditions may be under-reported and patients would likely benefit from increased surveillance efforts. ${ }^{10}$

Current guidelines do not mention FAST as a form of postcardiac arrest care. ${ }^{11} 12$ Routine FAST may be appropriate for

A

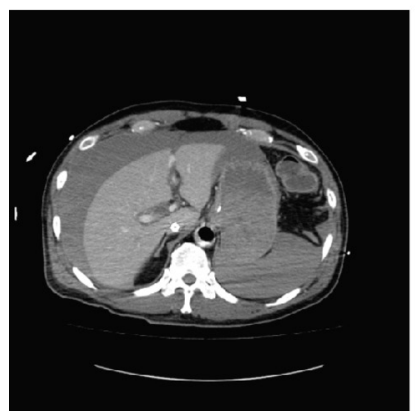

B

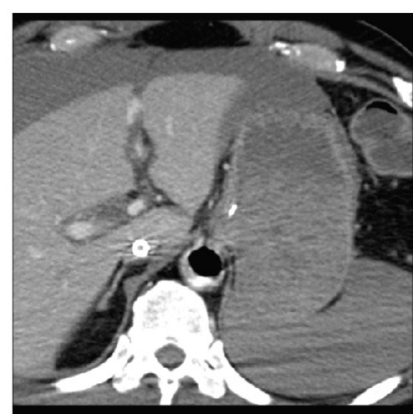

Figure $2(A, B)$ Late phase abdominal $C T$ with contrast. The range of the contrast effect expands.

patients who are hemodynamically unstable following resuscitation because of the common language shared among clinical practice, education and research. FAST may have wide applicability to emergency medical care, particularly with respect to trauma treatment. ${ }^{9}$

\section{Learning points}

- Liver trauma is a rare yet recognised complication of cardiopulmonary resuscitation that may be difficult to detect.

- The focused assessment with sonography for trauma (FAST) procedure can quickly and easily diagnose liver trauma.

- FAST is recommended for excluding haemoperitoneum in patients who are hemodynamically unstable following resuscitation.

Contributors HN and YT: planning, acquisition of data and interpretation of data. $\mathrm{HN}$ and MO: resources. $\mathrm{HN}$ and YM: supervision. $\mathrm{HN}$ : visualization and writing of original draft. All authors: writing, review and editing.

Competing interests None declared.

Patient consent Obtained from guardian.

Provenance and peer review Not commissioned; externally peer reviewed.

Open Access This is an Open Access article distributed in accordance with the Creative Commons Attribution Non Commercial (CC BY-NC 4.0) license, which permits others to distribute, remix, adapt, build upon this work non-commercially, and license their derivative works on different terms, provided the original work is properly cited and the use is non-commercial. See: http://creativecommons.org/ licenses/by-nc/4.0/

(c) BMJ Publishing Group Ltd (unless otherwise stated in the text of the article) . All rights reserved. No commercial use is permitted unless otherwise expressly granted.

\section{REFERENCES}

1 Meron G, Kurkciyan I, Sterz F, et al. Cardiopulmonary resuscitation-associated Major liver injury. Resuscitation 2007;75:445-53.

2 Camden JR, Carucci LR. Liver injury diagnosed on computed tomography after use of an automated cardiopulmonary resuscitation device. Emerg Radiol 2011;18:429-31.

3 Krischer JP, Fine EG, Davis JH, et al. Complications of cardiac resuscitation. Chest 1987;92:287-91.

4 Rosen J, Tuchek JM, Hartmann JR. Liver laceration in the hemodynamically unstable post-cardiac massage patient: early recognition and management--case report. J Trauma 1999:47:408-9.

5 Adams HA, Schmitz CS, Block G, et al. [Intra-abdominal bleeding after myocardial infarction with cardiopulmonary resuscitation and thrombolytic therapy]. Anaesthesist 1995:44:585-9.

6 Pezzi A, Pasetti G, Lombardi F, et al. Liver rupture after cardiopulmonary resuscitation (CPR) and thrombolysis. Intensive Care Med 1999:25:1032.

7 Druwé PM, Cools FJ, De Raedt HJ, et al. Liver rupture after cardiopulmonary resuscitation in a patient receiving thrombolytic therapy. Resuscitation 1996:32:213-6.

8 Körner M, Krötz MM, Degenhart C, et al. Current role of emergency US in patients with Major trauma. Radiographics 2008;28:225-42.

9 Sheng AY, Dalziel P, Liteplo AS, et al. Focused Assessment with Sonography in Trauma and Abdominal Computed Tomography utilization in adult trauma patients: trends over the last decade. Emerg Med Int 2013;2013:1-7.

10 Saptarshi B, Allisa A, Marcus L, et al. Cardiopulmonary resuscitation complicated by traumatic hepatic laceration: a Case Report and Review of Literature. J Med Cases 2017:8:93-7.

11 Nolan JP, Hazinski MF, Aickin R, et al. Part 1: executive summary: 2015 Internationa Consensus on Cardiopulmonary Resuscitation and Emergency Cardiovascular Care Science with treatment recommendations. Resuscitation 2015:95:e1-e32.

12 Soar J, Nolan JP, Böttiger BW, et al. European Resuscitation Council guidelines for resuscitation 2015: section 3. adult advanced life support. Resuscitation 2015;95:99-146 
Copyright 2017 BMJ Publishing Group. All rights reserved. For permission to reuse any of this content visit http://group.bmj.com/group/rights-licensing/permissions.

BMJ Case Report Fellows may re-use this article for personal use and teaching without any further permission.

Become a Fellow of BMJ Case Reports today and you can:

- Submit as many cases as you like

- Enjoy fast sympathetic peer review and rapid publication of accepted articles

Access all the published articles

- Re-use any of the published material for personal use and teaching without further permission

For information on Institutional Fellowships contact consortiasales@bmjgroup.com

Visit casereports.bmj.com for more articles like this and to become a Fellow 